\title{
Percutaneous Coronary Intervention: Safety of Methotrexate and Its Possible Benefits on Restenosis After Bare-Metal Stent Deployment
}

\author{
Viviane Gouveia $^{\mathrm{a}}$, Dinaldo C. Oliveira ${ }^{\mathrm{a}, \mathrm{b}}$, Emmanuele Tenorio $^{\mathrm{a}}$, Norma Brito ${ }^{\mathrm{a}}$, \\ Emanuel Sarinho ${ }^{\mathrm{a}}$
}

\begin{abstract}
Background: Percutaneous coronary intervention (PCI) revolutionized treatment of coronary artery disease. Drug-eluting stents are effective and safe but their cost is high, especially for some countries. The primary objective was to evaluate the safety of methotrexate (MTX) in patients who underwent PCI and the secondary goal was to evaluate the possibility that MTX has an impact on restenosis.
\end{abstract}

Methods: This was a transversal, prospective and descriptive study that recruited 16 patients in whom PCI was planned. MTX was administered to patients at a dose of $5 \mathrm{mg}$ /week for 2 weeks before PCI and 8 weeks after PCI. Bare-metal stent (BMS) deployment was performed according to standard practice. Patients were monitored clinically every 15 days during the first 2 months after the procedure and monthly until 9 months after PCI.

Results: There were no immediate or late complications associated with PCI. Adverse events and side effects due to MTX occurred in three patients (prevalence 18.7\%). These side effects are classified as minor complications. MTX was not discontinued due to these side effects. There were no reported cases of clinical restenosis.

Conclusions: MTX was safe in the study population and raised the possibility that a low-cost drug may have positive effects on restenosis after BMS implantation. However, studies with larger sample sizes and other imagine modalities (intravascular ultrasound and/or optical coherence tomography) are required to confirm this hypothesis.

Keywords: Coronary artery disease; Stent; Methotrexate; Restenosis

\footnotetext{
Manuscript accepted for publication June 02, 2016

${ }^{a}$ Hospital das Clinicas, Federal University of Pernambuco, Brazil ${ }^{b}$ Corresponding Author: Dinaldo C. Oliveira, Rua Irene Ramos Gomes de Matos, 68, ap 401, CEP 51011530, Recife, Pernambuco, Brazil.

Email:dinaldo@cardiol.br
}

doi: http://dx.doi.org/10.14740/cr468w

\section{Introduction}

Percutaneous coronary intervention (PCI) revolutionized treatment of coronary artery disease (CAD); to date, it is the most commonly used myocardial revascularization method in cardiology [1-3].

Drug-eluting stents (DESs) can markedly reduce restenosis and have become the most commonly used devices in interventional cardiology for treatment of coronary stenosis [1]. Although this technique does not completely abolish restenosis, a drastic reduction due to significant decrease in neointimal hyperplasia has been reported [4].

On the other hand, the rate of restenosis bare-metal stent (BMS) varies according to clinical setting, patient and angiographic characteristics, with rates as high as $60 \%[5,6]$. Oral drugs for reduction of restenosis are not a practice in interventional cardiology because studies performed did not support it $[6,7]$. Several studies that evaluated oral administration of sirolimus or immunosuppressants after BMS deployment have reported reduced neointimal hyperplasia compared with BMS alone; however, this reduction was not sufficient to allow their clinical use $[7,8]$.

Increased knowledge of restenosis pathophysiology after stent implantation in the past decade has helped to explain why certain drugs were not effective when administered orally.

Methotrexate (MTX) is a folate antagonist that blocks the S-phase of cell division, consequently blocking mitosis. Moreover, it has potent anti-inflammatory activity [9]. This drug was initially developed for cancer treatment; however, it has been used to treat rheumatic diseases including rheumatoid arthritis (RA) and psoriasis [9].

In this study, the primary objective was to evaluate the safety of oral administration of MTX to patients with severe $\mathrm{CAD}$ and the secondary goal was to evaluate the possibility that MTX has an impact on restenosis after BMS deployment.

\section{Materials and Methods}

This was a transversal, prospective and descriptive study that recruited 16 patients in whom PCI was planned from January to December 2016. This study followed the ethical principles in clinical research and was approved by ethics committee and all patients signed the informed consent. 
Table 1. Social Economic Characteristics of the Patients

\begin{tabular}{lll}
\hline Social economic characteristics & N & \% \\
\hline Sex & & \\
$\quad$ Male & 11 & 68.7 \\
$\quad$ Female & 5 & 31.3 \\
Scholarity & & \\
$\quad$ Illiterate & 2 & 12.5 \\
$\quad$ Elementary school & 11 & 68.7 \\
$\quad$ Fundamental school & 3 & 18.8 \\
\hline Skin color & & \\
$\quad$ White & 9 & 56.2 \\
$\quad$ Non-white & 7 & 43.8 \\
Monthly income & & \\
$\quad$ Minimum wage & 12 & 75.0 \\
$\quad$ Higher than minimum wage & 4 & 25.0 \\
\hline Neighborhood & & \\
$\quad$ Within Recife Metropolitan Region & 8 & 50.0 \\
$\quad$ Outside Recife Metropolitan Region & 8 & 50.0 \\
Habitation type & & \\
$\quad$ With basic sanitation & 15 & 93.8 \\
$\quad$ Without basic sanitation & 1 & 6.2 \\
\hline
\end{tabular}

The inclusion criteria were: age $>18$ years, one vessel disease with de novo lesion $>70 \%$ and moderate or severe ischemia according to myocardium scintigraphy for which optimal medical therapy was taken, and one of the following: diabetes mellitus (DM); reference vessel diameter $<2.5 \mathrm{~mm}$; or chronic kidney disease stages $\geq$ III associated with reference diameter of the target vessel $<2.75 \mathrm{~mm}$.

The exclusion criteria were: contraindications to MTX administration; severe lung disease; liver or kidney disease; and inability to undergo cine coronary angiography at follow-up.

The degree of coronary stenosis was assessed by visual analysis. Patients with stenosis $\geq 70 \%$, requiring PCI, were potentially candidates to be enrolled and the study was explained to them and those that accepted assigned the informed consent.

Anamnesis, physical examinations were performed to collect clinical and laboratory data. Data were collected using a questionnaire.

MTX was administered to patients at a dose of $5 \mathrm{mg} /$ week for 2 weeks before PCI and 8 weeks after PCI. BMS deployment was performed according to standard practice. All patients were under dual antiplatelet therapy (aspirin + clopidogrel).

Patients were monitored clinically every 15 days during the first 2 months after the procedure and monthly until 9 months after PCI. Coronary angiographs were performed in all patients 9 months after PCI due to protocol.

Clinical restenosis was defined as the occurrence of acute coronary syndrome or stable coronary disease with positive ischemia detection test (moderate or severe ischemia). Angio-
Table 2. Clinical Characteristics of the Patients

\begin{tabular}{lll}
\hline Risk factors and comorbidities & N & \% \\
\hline Hypertension & 15 & 93.8 \\
Previous angina & 14 & 87.5 \\
Dyslipidemia & 13 & 81.3 \\
Family history of CAD & 13 & 81.3 \\
Physical inactivity & 11 & 68.8 \\
Previous acute myocardial infarction & 8 & 50.0 \\
Smoking & 8 & 50.0 \\
Diabetes mellitus & 7 & 43.8 \\
Alcoholic & 4 & 25.0 \\
\hline
\end{tabular}

CAD: coronary artery disease.

graphic restenosis was defined as $\geq 50 \%$ in-stent stenosis or within $10 \mathrm{~mm}$ proximal or distal to stent $[6,10]$.

The complications associated with the procedures evaluated included hematoma, allergic reaction, pseudoaneurysm, infections, acute myocardial infarction (AMI), stroke, emergency surgery, retroperitoneal bleeding, arteriovenous fistula, and death.

The following complications associated with the use of MTX were evaluated: erythematous rash, pruritus, urticaria, photosensitivity, depigmentation, alopecia, ecchymosis, acne, furunculosis, bone marrow depression, leukopenia, thrombocytopenia, anemia, hypogammaglobulinemia, hemorrhage, septicemia, gingivitis, pharyngitis, stomatitis, anorexia, vomiting, diarrhea, hematemesis, melena, gastrointestinal ulceration, enteritis, liver disease, fatty change, renal failure, azotemia, cystitis, hematuria, menstrual dysfunction, abortion, birth defects, severe nephropathy, interstitial pneumonitis, headache, drowsiness and blurred vision, hemiparesis, aphasia, paresis, and convulsions.

The statistical analysis was done using SPSS Statistics for Windows, version 21.0. A descriptive analysis was performed and the numerical variables were presented as mean and standard deviation after the normal distribution of the data has been tested by Shapiro-Wilks. Categorical variables were described as percentages.

\section{Results}

There was a predominance of male participants, the average age was $62.4 \pm 8.3$ years, and majority of the patients had an elementary school level of education. Other clinical and sociodemographic characteristics are shown in Tables 1 and 2.

Analysis of coronary angiograms revealed 26 severe, 21 moderate, and 18 mild stenosis cases. Of note, eight patients had single-vessel disease, five had two-vessel disease, and three had multi-vessel disease. Coronary artery stenosis was more prevalent in the left anterior descending artery (LDA) (Table 3).

The average diameter and length of the stents were $3.0 \pm$ 0.4 and $18.1 \pm 5.9 \mathrm{~mm}$, respectively, as shown in Table 4. 
Table 3. Moderated and Severe Arterial Lesions in Coronary Arteries

\begin{tabular}{llll}
\hline Coronary artery & Moderate lesions $(\geq \mathbf{5 0 \%})$ & Severe lesions $(\geq \mathbf{7 0} \%)$ & Total \\
\hline Anterior descending artery & 9 & 7 & 16 \\
Left circumflex artery & 8 & 7 & 15 \\
Right coronary artery & 2 & 12 & 14 \\
Left main & 2 & 0 & 2 \\
Total & 21 & 26 & 47 \\
\hline
\end{tabular}

There were no immediate or late complications associated with PCI. Adverse events and side effects due to use of MTX occurred in three patients (prevalence 18.7\%). Of note, two patients had skin desquamation on the extremities of the upper limbs and one patient had dryness of the oral mucosa. These side effects are classified as minor complications. The MTX was not discontinued due to these side effects. When the patients finished the MTX due to protocol, they were healed.

There were no reported cases of clinical restenosis. Only one patient had angiographic restenosis (prevalence was 6.2\%; however, her myocardial perfusion imagining did not show ischemia).

\section{Discussion}

Based on the few side effects observed, this study demonstrated the safety of MTX administration in this study population (patients with severe CAD). In addition, these complications did not result in treatment withdrawal. MTX has been used for treatment of patients with rheumatic disease and the rate of

Table 4. Diameter and Length of the Stents $(\mathrm{mm})$

\begin{tabular}{lll}
\hline Patient & Stent diameter & Stent length \\
\hline 1 & 3.0 & 23 \\
2 & 2.5 & 23 \\
3 & 2.5 & 16 \\
4 & 2.5 & 23 \\
5 & 2.5 & 13 \\
6 & 3.5 & 16 \\
7 & 3.0 & 20 \\
8 & 3.5 & 19 \\
9 & 2.5 & 15 \\
10 & 2.75 & 15 \\
11 & 3.5 & 18 \\
12 & 3.5 & 24 \\
13 & 3.0 & 24 \\
14 & 2.5 & 18 \\
15 & 3.0 & 15 \\
16 & 3.0 & 28 \\
Mean (standard deviation) & $3.0(0.4)$ & $18.1(5.9)$ \\
\hline
\end{tabular}

side effects is low.

There were no reported cases of clinical restenosis. Coronary angiography performed at 9-month follow-up showed that angiographic restenosis was low. These results are quite satisfactory considering the clinical and angiographic characteristics of the patients enrolled.

Neointimal hyperplasia is the primary component of restenosis after stent deployment. Vascular injury occurs, followed by a reparative process, in which migration of vascular smooth muscle cells (VSMC) occurs from the medial layer into the intima, cellular multiplication, and cellular secretion of molecules. These events play an important role in the formation of neointimal hyperplasia [11].

DESs have been used as a platform to carry and release drugs at the site of injuries resulting from PCIs. The drugs most commonly used in clinical practice are sirolimus (and its analogues) and paclitaxel. These types of DES reduce the chance of restenosis up to $70 \%$ compared to BMS [12-18].

DESs with some cell mitosis inhibitors, such as dexamethasone and tacrolimus, have not shown sufficiently positive effects in pre-clinical and clinical studies to allow their use in clinical practice [19].

The prevalence of angiographic restenosis after BMS deployment is up to $60 \%$. Despite many attempts to reduce restenosis rates, only reduction of the stent structure thickness resulted in reduced restenosis [6].

Reduction of restenosis was attempted by oral drug administration. However, the results of the drugs tested were not satisfactory enough to warrant their incorporation into clinical practice $[7,20]$.

Some studies, including the oral sirolimus to inhibit recurrent in-stent stenosis (OSIRIS), oral rapamune to inhibit restenosis (ORBIT), and prospective, randomized oral rapamycin in Argentina (ORAR) studies, as well as other investigations, evaluated oral use of sirolimes and reported an intermediate efficacy. However, these drugs caused many major side effects, which may have contributed to the lack of interest for phase-III clinical trials [20-23].

The high prevalence of side effects reported in these studies was surprising considering that sirolimus (rapamycin) has been used in transplanted patients and this high frequency of side effects had not been previously reported [8].

Authors evaluated the neointimal hyperplasia of transplanted kidney patients (taking immunosuppressive therapy) that underwent BMS implantation and reported that neointimal hyperplasia was minimal and determined $9 \%$ of vessel obstructions [24]. 
Some studies evaluated the use of MTX and restenosis after PCI. In this context, in 1992, an animal study evaluated, among other aspects, whether MTX would have any effect on neointimal hyperplasia after stent deployment. The authors concluded that the amount of neointima did not differ from the amount obtained after using stents alone $[25,26]$.

Two decades after this study, some considerations need to be made about these findings. The stent used in this study was a coil. Nowadays, this type of stent is out of market because it did not have good outcomes in clinical studies. The kinetic of drug release was not appropriate because the majority of the drug had been released from the stent during the first hour after deployment. According to stent design, only a small percentage of the drug was released to the vessel wall. These release kinetics are considered unacceptable considering recent standards for any experiment involving DESs.

In this study, the balloon-artery ratio was above $1: 1.2$. It is known that this kind of model is related to higher possibility of great amount of hyperplasia. Therefore, the large amount of drug delivered in the first hour, the small amount of drug delivered to the vessel wall, and the balloon-artery ratio are factors that may raise doubts about the authors' conclusions.

In 2004, a study was published that compared MTX-eluting stents to SAE-coated stents which was done in pigs. In this experiment, the stent-artery ratio was $1: 1$ and $50 \%$ of the drug had been released by $24 \mathrm{~h}$. The results showed that MTXeluting stents reduced neointimal hyperplasia $(1.22 \pm 0.34 \mathrm{vs}$. $2.25 \pm 1.28 \mathrm{~mm}, \mathrm{P}<0.01)$ and in-stent obstruction $(21 \pm 8 \%$ vs. $36 \pm 21 \%, \mathrm{P}<0.01)$ [26].

Another aspect that deserves attention was the finding that MTX had no effect on cell proliferation in vitro. However, this conclusion was based on an experiment that used cells derived from rabbit aortas and not from stent-treated pigs, which were the basis of the study.

We should imagine how neointimal hyperplasia could have been reduced in this study if MTX had no effect on VSMC proliferation. Therefore, we hypothesize that other mechanisms leading to hyperplasia reduction, e.g. inactivation of the secretory function of VSMC or the effect of MTX on the proliferation of VSMC from rabbit aortas was different from that on pig cells may justify this matter.

One case-control study evaluated 228 lesions in patients with RA taking MTX and 677 lesion controls treated by PCI. Both groups were followed for a mean of 3.8 years. In the RA group, patients treated with MTX or TNF inhibitors showed significantly less target vessel revascularization [27].

Davis et al evaluated the relationship between polymorphisms in the enzyme methylenetetrahydrofolate reductase (MTHFR) and cardiovascular events in 1,047 subjects. They did not find any type of association between MTHFR and cardiovascular events in RA, while MTX use was protective against these events [28].

In addition, our results allow us to hypothesize that MTX may have beneficial effects on restenosis. It is of note that administration of MTX for 15 days before PCI and its maintenance for 60 days aimed to block inflammation, considered one of the triggers for formation of the neointimal hyperplasia, and mitosis. At the time of the previous studies on MTX, the importance of the kinetic of drug release was not well known.
The efficacy of DES is high and its safety has improved in second- and third-generation devices. However, high costs have limited the introduction of this type of material on a large scale in underdeveloped or developing countries [29-31].

Therefore, the search for low-cost therapies that have a positive effect on restenosis is extremely important for patients living in countries with limited financial resources. Furthermore, the feasibility of effective and safe therapies that are not used in the population due to their high cost should be addressed.

\section{Conclusions}

MTX was safe in the study population and raised the possibility that a low-cost drug may have positive effects on restenosis after BMS implantation. However, studies with larger sample sizes and other imagine modalities (intravascular ultrasound and/or optical coherence tomography) are required to confirm this hypothesis.

\section{Conflicts of Interest}

The authors declare no conflicts of interest.

\section{Financial Disclosure}

None.

\section{References}

1. Kubo S, Kadota K, Otsuru S, Hasegawa D, Habara S, Tada $\mathrm{T}$, Tanaka H, et al. Everolimus-eluting stent implantation versus repeat paclitaxel-coated balloon angioplasty for recurrent in-stent restenosis lesion caused by paclitaxelcoated balloon failure. EuroIntervention. 2015;10(9):e18.

2. Almeida RMS. Myocardial revascularization: comparative cost study between conventional coronary bypass and percutaneous transluminal coronary angioplasty. Rev Bras Cir Cardiovasc. 2005;20:142-148.

3. Koskinas KC, Chatzizisis YS, Antoniadis AP, Giannoglou GD. Role of endothelial shear stress in stent restenosis and thrombosis: pathophysiologic mechanisms and implications for clinical translation. J Am Coll Cardiol. 2012;59(15):1337-1349.

4. Kim MS, Dean LS. In-stent restenosis. Cardiovasc Ther. 2011;29(3):190-198.

5. Beohar N, Davidson CJ, Kip KE, Goodreau L, Vlachos HA, Meyers SN, Benzuly KH, et al. Outcomes and complications associated with off-label and untested use of drug-eluting stents. JAMA. 2007;297(18):1992-2000.

6. Eeckhout E, Serruys PW, Wijins W, Vahanian A, Sambeek MV, De Palma R. Percutaneous Interventional Cardiovascular Medicine: The PCR-EAPCI Textbook. PCR Publishing, Minneapolis, MN, USA Europe: Europa Edi- 
tion, 2012.

7. Chaves AJ, Sousa AG, Mattos LA, Abizaid A, Feres F, Staico R, Centemero M, et al. Pilot study with an intensified oral sirolimus regimen for the prevention of in-stent restenosis in de novo lesions: a serial intravascular ultrasound study. Catheter Cardiovasc Interv. 2005;66(4):535540 .

8. Montalbano M, Neff GW, Yamashiki N, Meyer D, Bettiol M, Slapak-Green G, Ruiz P, et al. A retrospective review of liver transplant patients treated with sirolimus from a single center: an analysis of sirolimus-related complications. Transplantation. 2004;78(2):264-268.

9. Tunali-Akbay T, Sehirli O, Ercan F, Sener G. Resveratrol protects against methotrexate-induced hepatic injury in rats. J Pharm Pharm Sci. 2010;13(2):303-310.

10. Dangas GD, Claessen BE, Caixeta A, Sanidas EA, Mintz GS, Mehran R. In-stent restenosis in the drug-eluting stent era. J Am Coll Cardiol. 2010;56(23):1897-1907.

11. Chaabane C, Otsuka F, Virmani R, Bochaton-Piallat ML. Biological responses in stented arteries. Cardiovasc Res. 2013;99(2):353-363.

12. Regar E, Serruys PW, Bode C, Holubarsch C, Guermonprez JL, Wijns W, Bartorelli A, et al. Angiographic findings of the multicenter Randomized Study With the SirolimusEluting Bx Velocity Balloon-Expandable Stent (RAVEL): sirolimus-eluting stents inhibit restenosis irrespective of the vessel size. Circulation. 2002;106(15):1949-1956.

13. Colombo A, Drzewiecki J, Banning A, Grube E, Hauptmann K, Silber S, Dudek D, et al. Randomized study to assess the effectiveness of slow- and moderate-release polymer-based paclitaxel-eluting stents for coronary artery lesions. Circulation. 2003;108(7):788-794.

14. Moses JW, Leon MB, Popma JJ, Fitzgerald PJ, Holmes DR, O'Shaughnessy C, Caputo RP, et al. Sirolimus-eluting stents versus standard stents in patients with stenosis in a native coronary artery. N Engl J Med. 2003;349(14):13151323.

15. Schampaert E, Cohen EA, Schluter M, Reeves F, Traboulsi M, Title LM, Kuntz RE, et al. The Canadian study of the sirolimus-eluting stent in the treatment of patients with long de novo lesions in small native coronary arteries (C-SIRIUS). J Am Coll Cardiol. 2004;43(6):11101115.

16. Tanabe K, Serruys PW, Grube E, Smits PC, Selbach G, van der Giessen WJ, Staberock M, et al. TAXUS III Trial: in-stent restenosis treated with stent-based delivery of paclitaxel incorporated in a slow-release polymer formulation. Circulation. 2003;107(4):559-564.

17. Hermiller JB, Raizner A, Cannon L, Gurbel PA, Kutcher MA, Wong SC, Russell ME, et al. Outcomes with the polymer-based paclitaxel-eluting TAXUS stent in patients with diabetes mellitus: the TAXUS-IV trial. J Am Coll Cardiol. 2005;45(8):1172-1179.

18. Stone GW, Ellis SG, Cannon L, Mann JT, Greenberg JD, Spriggs D, O'Shaughnessy CD, et al. Comparison of a polymer-based paclitaxel-eluting stent with a bare metal stent in patients with complex coronary artery disease: a randomized controlled trial. JAMA. 2005;294(10):12151223.
19. Aslanabadi N, Separham A, Beheshti R, Ghaffari S, Sohrabi B. OPTIMA Tacrolimus-eluting Stent: A Twelvemonth Clinical Follow up with Two Different Periods of Dual Antiplatelet Therapy; 2-month vs. 6-month Approach. J Cardiovasc Thorac Res. 2012;4(3):81-84.

20. Brito FS, Jr., Rosa WC, Arruda JA, Tedesco H, Pestana JO, Lima VC. Efficacy and safety of oral sirolimus to inhibit in-stent intimal hyperplasia. Catheter Cardiovasc Interv. 2005;64(4):413-418.

21. Hausleiter J, Kastrati A, Mehilli J, Vogeser M, Zohlnhofer D, Schuhlen H, Goos C, et al. Randomized, double-blind, placebo-controlled trial of oral sirolimus for restenosis prevention in patients with in-stent restenosis: the Oral Sirolimus to Inhibit Recurrent In-stent Stenosis (OSIRIS) trial. Circulation. 2004;110(7):790-795.

22. Waksman R, Ajani AE, Pichard AD, Torguson R, Pinnow E, Canos D, Satler LF, et al. Oral rapamycin to inhibit restenosis after stenting of de novo coronary lesions: the Oral Rapamune to Inhibit Restenosis (ORBIT) study. J Am Coll Cardiol. 2004;44(7):1386-1392.

23. Rodriguez AE, Rodriguez Alemparte M, Vigo CF, Fernandez Pereira C, Llaurado C, Vetcher D, Pocovi A, et al. Role of oral rapamycin to prevent restenosis in patients with de novo lesions undergoing coronary stenting: results of the Argentina single centre study (ORAR trial). Heart. 2005;91(11):1433-1437.

24. Arruda JA, Costa MA, Brito FS, Jr., Tedesco H, Barbosa AH, Ribeiro EP, Pestana JO, et al. Effect of systemic immunosuppression on coronary in-stent intimal hyperplasia in renal transplant patients. Am J Cardiol. 2003;91(11):1363-1365.

25. Cox DA, Anderson PG, Roubin GS, Chou C, Agrawal SK, Cavender B. Effect of local delivery of heparin and methotrexate on neointimal proliferation in stented porcine coronary arteries. Coron Artery Dis. 1992;3:237248.

26. Huang Y, Salu K, Liu X, Li S, Wang L, Verbeken E, Bosmans J, et al. Methotrexate loaded SAE coated coronary stents reduce neointimal hyperplasia in a porcine coronary model. Heart. 2004;90(2):195-199.

27. Sintek M, Sparrow C, Novak E, Singh J. Increased risk of repeat coronary revascularization is reduced by methotrexate or tumor necrosis factor inhibitor treatments in patients with rheumatoid arthritis. Circulation. 2014;(130 SUPPL):2.

28. Davis LA, Cannon GW, Pointer LF, Haverhals LM, Wolff RK, Mikuls TR, Reimold AM, et al. Cardiovascular events are not associated with MTHFR polymorphisms, but are associated with methotrexate use and traditional risk factors in US veterans with rheumatoid arthritis. J Rheumatol. 2013;40(6):809-817.

29. Stone GW, Midei M, Newman W, Sanz M, Hermiller JB, Williams J, Farhat N, et al. Randomized comparison of everolimus-eluting and paclitaxel-eluting stents: twoyear clinical follow-up from the Clinical Evaluation of the Xience V Everolimus Eluting Coronary Stent System in the Treatment of Patients with de novo Native Coronary Artery Lesions (SPIRIT) III trial. Circulation. 2009;119(5):680-686. 
30. Jensen LO, Thayssen P, Christiansen EH, Tilsted HH, Maeng M, Hansen KN, Kaltoft A, et al. 2-year patientrelated versus stent-related outcomes: the SORT OUT IV (Scandinavian Organization for Randomized Trials With Clinical Outcome IV) Trial. J Am Coll Cardiol. 2012;60(13):1140-1147.
31. Kandzari DE, Leon MB, Popma JJ, Fitzgerald PJ, O'Shaughnessy C, Ball MW, Turco M, et al. Comparison of zotarolimus-eluting and sirolimus-eluting stents in patients with native coronary artery disease: a randomized controlled trial. J Am Coll Cardiol. 2006;48(12):24402447. 